\title{
Barriers to Appropriate Technology Growth in Sustainable Development
}

\author{
I. Zelenika \\ School of Environmental Studies, Queen's University \\ 60 Union Street, Kingston, Ontario, K7L 3N6, Canada \\ E-mail: ivana.zelenika@queensu.ca
}

J. M. Pearce (Corresponding author)

Department of Materials Science \& Engineering and Department of Electrical \& Computer Engineering,

Michigan Technological University

1400 Townsend Dr., Houghton, MI 49931, USA

Tel: 906-487-1466 E-mail: pearce@mtu.edu

Received: September 9, $2011 \quad$ Accepted: September 22, $2011 \quad$ Published: December 1, 2011

doi:10.5539/jsd.v4n6p12 URL: http://dx.doi.org/10.5539/jsd.v4n6p12

The research is financed by The Social Sciences and Humanities Research Council and The Natural Sciences and Engineering Research Council of Canada.

\begin{abstract}
Given the urgency of development problems world-wide, as well as the opportunities of open source appropriate technology (OSAT) to help expedite sustainable development goals, a better understanding of the barriers limiting the scaling of OSAT is needed. In this study, key organizations and researchers working in the field of appropriate technology (AT) were interviewed to identify barriers to OSAT. The data was analyzed via pattern coding and content analysis. Results reveal that among the most pressing problems for those working in the field of AT were the need for better communication and collaboration between the agencies and communities to share the knowledge and resources, and to work in partnership. Specific barriers include: i) AT seen as inferior or "poor person's" technology, ii) technical transferability and robustness of AT, iii) insufficient funding, iv) weak institutional support, and v) the challenges of distance and time in tackling rural poverty. Finally, future work is outlined to better understand and overcome these barriers.
\end{abstract}

Keywords: Appropriate technology, Crowd sourcing, Internet, Knowledge commons, Online collaboration, Open source, Open source appropriate technology, Sustainable development

\section{Introduction}

The urgency of reaching sustainable development goals has never been more critical given the rising world population, continued climate destabilization, peak oil and the effects of other potential resource scarcities in all parts of the world (IPCC, 2007; UN 2010). In addition, the majority of the Millennium Development Goals are still out of reach (Black, 2007; WHO 2010), and some argue that despite the billions of dollars of aid distributed since 1950s, there is very little palpable improvement for the world' s poorest regions (Black, 2007). The urgency is easy to understand: about 2.6 billion people on the planet have no access to safe drinking water or hygienic toilets (WHO, 2010), 4 billion people sustain themselves and their families on less than \$2 per day (UN, 2010), while over 1 billion people are estimated to live in dire poverty surviving on less than $\$ 1$ a day. Furthermore, approximately 10.8 million children under the age of five die each year from preventable causes (WHO, 2007), of which access to safe drinking water, proper sanitation and nutrition are the most pressing and most preventable.

While a generally agreed upon component of development includes a successful technology transfer, development of any form is a very complex process because it functions within equally complex social, technical, political and economic variables. Even within the technological components of development alone there are 
variables whose positive and negative effects cannot always be fully foreseen or predicted (Smillie, 2000). Smith explains in Science and Technology for Development that "No matter how tightly science and technology are entwined with development, the relationship only ever reflects a slice of all of which that development represents" (Smith, 2009). Thus, history has no shortage of failed attempts of transferring foreign highly-mechanized and energy-intensive technologies in anticipation of a successful uptake, or in poor assumptions of technical results being identical in different geographical, social and political realms (Chambers, 1983; Carr, 1985; Black, 2007; Smith, 2009). Too often the emphasis of projects focuses solely on technology, or the wrong type of technology that does not match particular cultural, social, economic or political circumstances (Schumacher, 1973; Chambers, 1983; Carr, 1985; Smith, 2009). Examples of blatant disregard for local conditions and sustainability include large-scale energy projects like dams that dislocate thousands and change landscapes and ecosystems, or introducing highly mechanized mono-agricultural machinery for straight line harvesting in areas where agriculture is small scale, community owned and engaged in poly-culture (Black, 2007). Other examples can be more subtle in severity, but also demonstrate complexity of development process and the importance of local conditions in project planning. Such examples include: i) introducing bicycle grinders to communities where traditionally women grind flour, but only men drive bicycles; ii) promoting smokeless cooking stoves for respiratory ailments when smoke helps communities combat mosquitoes and malaria; or iii) building solar cookers in places where traditional meals are served in late evening (Ryan and Vivekananda, 1993). The reality of development is such that even when all of the proper feasibility studies and planning take place, the integration of any new or modified component to people's lives is not without an effect. This is especially the case when it comes to introduction of technology (Tenner, 1997; 2004). Adding technological elements to any social, political or economic fabric can react in unexpected ways because technology itself is influenced by those elements in which it operates. James Smith explains: "All technologies carry with them risks, be they foreseen, unforeseen, or little understood. Conversely, the benefits of technologies may be far greater than we can foresee. We respond to these uncertainties by attempting to maximize the benefits and minimize the risks of technological change." (Smith, 2009). In the same sense, as technology does not function isolated from social relationships (Carr, 1985; Thomas, 1994; Smith, 2009), and yet even the simplest of technologies can improve and save lives, more emphasis and research is needed on ways technology is introduced, designed and transferred into developing communities, and how to improve the process.

A great cause for optimisms is in the fact that aid funding is growing globally (UN, 2010), and so are the number of agencies working in the field of sustainable development. Sustainable development today can be given a more rigorous definition than used commonly by WCED (1987), as being defined as that which leads to societies which live within the self-perpetuating limits of its environment. That society is not necessarily a no growth society, it is rather a society that recognizes the limits of conventional growth and looks for alternative ways of development (Coomer; 1979). In addition, there is a renewed interest in the field of appropriate technology (AT) for sustainable development (Buitenhuis et al., 2010). Appropriate technology can be defined as such technologies that fit local conditions and are easily and economically utilized from readily available resources by local communities to meet their needs (Sawhney et al., 2002; Buitenhuis et al., 2010). As such, AT criteria can incorporate innovations such as water purifiers, irrigation systems, biodigesters, food grinders, processors and solar cookers, but can also include more 'high-tech' or complex technologies such as solar photovoltaic powered lanterns, electricity generation, cell-phones and computers, which are becoming integral components of many developing communities (Arunachalam, 2002; Tcheeko et al., 2006; Ashraf et al., 2007). As Ian Smillie points out in Mastering the Machine: Poverty, Aid and Technology: "The issue for developing countries is not a trade-off between high and low technologies: it is a trade-off between appropriate and inappropriate technologies" (Smillie, 2000). The positive impact of relatively simple life saving technologies such as water purification systems could make is substantial (Hashmi \& Pearce, 2011), and yet the research and development (R\&D) investments in AT have been declining over the decades compared to the continuous investment in research of large-scale high-tech techniques (Jequier, 1976; Carr, 1985; Pursell, 1993; NCAT, 2011). As such, despite more than a quarter century of development, there has not yet been much uptake of AT in research or as a principle means of enabling sustainable development by most development organizations, donors, or the mainstream public. In addition, while there are a growing number of organizations, researchers and communities working on facilitating sustainable development through AT all around the world, the full capacity and potential of that research and knowledge is largely untapped because it is not often published or shared with the communities who need the information (Pearce et al., 2011). The research tends to be scattered and very much influenced by trial and error because of work happening in isolation (Pearce, 2007; Buitenhuis et al., 2010). Therefore, it has been proposed that using the open collaborative principles from the highly successful open source software movement, which is currently responsible for over 50\% of Internet software (Deek \& McHugh, 2008; Netcraft 
Web, 2011), collaborative open source appropriate technology (OSAT) design could significantly improve development efforts all around the world (Sawhney, 2002; Buitenhuis et al., 2010; Pearce et al., 2011). The open source component of AT would allow for continuous improvements of development solutions because knowledge and technologies would be shared and built on collaboratively. In fact, open source innovation, crowd-sourcing and collaborative work are growing in application worldwide (Benkler, 2006; Chesbrough, 2003; Watson, 2009) and the same principles can also be instrumental to development efforts. Further advances in information and communication technology software and hardware have allowed for new ways disseminate information via wikis, Internet and mobile phones, making the plausibility of OSAT a reality (Sawhney, 2002; Pearce \& Mushtaq, 2009; Buitenhuis et al., 2010). Early studies and examples of this topic shows that the collaborative design processes, appropriate tools, and access to technical information enables more effective and rapid development of AT for both industrialized and non-industrialized regions (Sawhney, 2002; Buitenhuis et al., 2010). Given the urgency of the development problems world-wide, as well as the opportunities of OSAT to help expedite sustainable development, the need to identify and diagnose the barriers to scaling up OSAT are clear. This study undertook interviews of key organizations and researchers working in the field of AT, as well as those involved with the open data movement, to identify barriers to OSAT and suggest solutions. The barriers from the interviews were compared to those previously identified in the literature, coded, analyzed and discussed with future work outlined.

\section{Background}

\subsection{Appropriate Technology for Sustainable Development}

AT was first conceptualized as 'intermediate technology' by the economist E.F. Schumacher in the 1970s in his influential book Small is Beautiful: Economics as if People Mattered (Schumacher, 1973). Schumacher's principles on economy and development were very much influenced by Buddhist philosophy, as well as his own work in developing countries as an economic adviser. Such experience prompted him to conclude that local self-reliance, meaningful work and development that match local conditions are the necessary requirements of any successful development project. He suggested how the most appropriate type of technologies for developing countries are likely to be a range of 'intermediate technologies' that are "more productive than the often labour-intensive, inefficient traditional technologies, but less costly and more manageable than the large scale, labour saving but capital intensive technologies of the industrialized society (Evans \& Adler, 1979). Inspired by permanence, Schumacher also called for a re-evaluation of the gross national product as the sole measure of development success and human happiness, and stressed the need for "meaningful, creative and purposeful work" utilizing "accessible, small scale and appropriate technology, which are compatible with human need for creativity" (Schumacher, 1973). In addition, Schumacher advocated for demand-led innovation of technologies that are elegant, low energy, economical and designed to match the purpose and needs of those that use it. In other words, less can be more when introducing appropriate tools and technologies that may seem smaller in scale and complexity, but will be utilized more effectively by the communities (Chambers 1983; Hazeltine \& Bull, 1999).

Today, AT is a concept based on sustainable and smart engineering, working within local contexts and environments, and designing with end-users in mind (Buitenhuis et al., 2010). The AT criteria incorporates small scale, sustainable technical innovations, including the theoretical 'know-how' or the software components of design and function, as well as traditional knowledge and biomimicry. A growing number of authors claim that the field of AT can be of significant assistance in sustainable development: namely provide food and water security, health, education, and also provide dignified work for world's millions (Schumacher, 1973; Jequier, 1976; Chambers, 1983; Carr, 1985; Hazeltine \& Bull, 1999; Smillie, 2000; Sawhney et al., 2002; Pearce \& Mushtaq, 2009; Buitenhuis et al., 2010). However, a number of barriers stand in the way of AT reaching more of a critical mass engagement and use. Some barriers are purely technical in nature, while others have roots in social, economical, geographical and political arenas, demonstrating the complex nature of the development process (Jéquier, 1976; Chambers, 1983; Carr, 1985; Hazeltine \& Bull, 1990; Smillie, 2000). Furthermore, the barriers are often interconnected and thus require even more rigors study and understanding to enable the fullest potential of OSAT.

\subsection{AT Barriers: Defining principles}

Even the definition of appropriate technology can be a significant barrier. If defined too rigidly, AT can be seen as holding back modernization and infringing on competitiveness by denying developing regions the same technology as in developed regions (Carr, 1985). Along the same vein, such arguments also give rise to a new form of neocolonialism implying that modern technology is not right for developing countries and therefore they 
should receive second-best or more primitive technology (Carr, 1985). This response to the concept of AT is common, yet none of these are actual implications of the AT principles because as the definition of AT indicates, the emphasis is on utilizing technology that works best for a given location and circumstance. If the technology in question is smaller in size, scale, cost, complexity, uses local materials, eliminates the need for patents and royalties, involves decentralized renewable sources of power, and is easy to operate and fix by local communities, then these are the advantages not the drawbacks. As Nicolas Jéquier explains in Appropriate Technology: Problems and Promises, "the aim of AT in principle is generally not to replace an existing industrial systems but to promote technological innovation in the areas where it is weak or ineffective" (Jéquier, 1976). Carr also reminds that the primary function of AT is to enhance the economic position of those who have not been given the opportunity to fully participate in the current development process - namely the rural, isolated and impoverished people (Carr, 1985). As such, the AT definition can vary depending on the circumstances. Understanding that what may be appropriate in some places may not be in others, especially given the changing nature of human societies and technology throughout the world, AT can also be defined as that which is appropriate for a particular community at that time and place in terms of size, scale and useability (Pursell, 1993). While this is a simple enough concept in theory, putting it to practice has been a challenge due to a multitude of additional barriers, as well as the difficulty of assessing technology appropriateness.

\subsection{AT Barriers: Technical Aspects}

Given the complexity of technological design, implementation and dissemination, constraints of permanence, robustness and transferability of AT to technical, political and economic spheres have also been identified as key barriers (Carr, 1985; Smith, 2009). No technology truly survives the test of time, given that human innovation never stops, but fundamental differences in the purchasing power of those living on $\$ 2$ a day, versus the rest of the world is the reason why AT has to be robust and durable to thrive (Pearce et al., 2011). Compounding the challenge yet further is the difference between rural and urban development and the complications they bring. Firstly, the barriers of distance and time make it difficult to tackle rural poverty, which is segregated from the mainstream and urban development and yet this is where development is needed the most (Chambers, 1983). Those living in rural areas may have similar needs to those living in urban areas, however many of the needs are drastically different and require equal attention (Chambers, 1983; Carr, 1985). In addition, technocratic over-emphasis, lack of institutional support, brain drain, ignorance and arrogance were also among the key barriers identified for rural development of AT (Chambers, 1983; Carr, 1985).

\subsection{AT Barriers: Organizational Aspects}

On an organizational level, barriers to successful AT implementation include access to stable funding, critical mass building and mainstream involvement, as well as a better institutional support for AT (Chambers 1983; Carr, 1985; Smillie, 2000). Other barriers include too much focus placed on the hardware only as opposed to the 'software' of the AT application, as well as outsider involvement often overshadowing the input of people for whom the technology is intended for, and on whom the success of AT depends (Carr, 1985). Considerable work is needed in ensuring a continuous feedback loop with the project stakeholders, and increasing the collaboration with the researchers in the field, as well as the communities employing the technology (Chambers, 1983; Black, 2007; Smith, 2009). In addition, more collaboration between researchers is needed to eradicate wheels being re-invented, lessons re-learned, as well as provide the solid knowledge base for continuous improvements and innovation for future (Pearce, 2007; Buitenhuis et al., 2010; Pearce et al., 2011).

\section{Methodology}

\subsection{Data Collection}

In total seventeen interviews were conducted with twenty one participants from the field of AT development and open data. The interviews followed the semi-structured 30 minute interview method as developed by Mikkelsen (1995), supplemented by informal conversational interview techniques (Babbie \& Rubin, 2007). As such the interviews provided a wide enough scope to examine possible barriers and offer qualitative data on the most pressing barriers, while allowing ample time for the interviewees to elaborate on general development topic, and share supplemental details they deemed necessary furthering the scope of the research.

Questions included inquiry on the barriers to development in general, as well as barriers to the appropriate technology and open source / open access of data in research. Attempts were also made to balance the types of the respondents, but time restrictions for the project limited the ability to obtain equal representation of respondents from all sectors involved in AT development. The final interview breakdown included responses from five academics working in the field of development, eight non-governmental organizations, one governmental, as well as feedback from two entrepreneurial organizations and two independent activists and 
researchers. The academic researchers included professors from Arizona University, Cooper Union, Hope College, St. Thomas and Western Washington University. Non-Governmental and Not for Profit Organizations participating in the interviews included: American Society of Mechanical Engineers (ASME), the Appropedia Foundation, Appropriate Technology Collaborative (ATC), Appropriate Infrastructure Development Group (AIDG), Compatible Technology International (CTI), Digital Green and Practical Action. Governmental agency input was provided by the Canadian Crown Corporation - International Development Research Center (IDRC). The research also included feedback from the entrepreneurial sector - AYZH and Kopernik, as well as open data movement activist David Eaves and development activist Vinay Gupta.

The majority of the prospective interviewees were chosen by the 'reputation method' style as devised by Laumann and Knocke (1987), which implies that respondents are selected based on their merit and reputation in the field. The field of AT is still growing, but there are about a dozen organizations and individuals considered at the forefront, which were thus chosen as the potential interview prospects. Several interviewees also came out of the process of peer recommendation from discussions at the NCIIA Conference in 2010. Once the University ethics board clearance was granted, prospective interviewees were contacted via e-mail or in person with an invitation to the research, outlining the background of the study, providing sample questions and the consent form. A majority of the prospective interviewees agreed to the interview, of which all but one granted the permission to record the talk, and all but one gave permission to use their name in publications. Four of the interviews were conducted in person; two were via an e-mail correspondence, while the rest were skype / phone interviews. As per the ethics guidelines, the interview data, including audio files, transcriptions and consent forms are stored in a locked location on an encrypted disc.

\subsection{Analysis Process}

Once completed the interviews were transcribed and coded for key barrier categories which were counted to assess their frequency while extrapolating themes, patterns and top barriers. To analyze the data two techniques were employed: logical and pattern coding. First, the interview responses were analyzed using logical analysis procedures based on Patton (1990), which explored emergent themes and barriers throughout the interviews and their frequency. Next, the pattern coding was employed to group summaries of data into smaller number of overarching or linked themes (Miles \& Huberman, 1984). Once all interviews were transcribed, key comments and responses were highlighted and coded via pattern grouping in regards to their relevance to social or technical barriers to AT, open access, and general development. The coded themes and their subsequent responses were then counted for frequency of use to provide numerical data and help identify the most pressing barriers.

\section{Results and Discussion}

Five barrier themes to OSAT development were identified through the process of coding the interviews: 1) social barriers, 2) communication and information specific barriers, 3) barriers to open source technology, 4) barriers to technology (AT or in general), and 5) social and technical barriers inter-connected. Figure 1 shows the frequency of response or the number of times certain barrier themes were brought up by the interviewees as a function of the five key coded categories.

As can be seen in Figure 1, the most often identified barriers were those that fell strictly in the social realm followed by communication and information category. Barriers to open source and technology in general were next biggest obstacles followed by the socio-economic category. To clarify: social barriers were those that dealt with culturally or socially specific undertones such as developing trusting relationships, particular cultural norms or dealing with socio-economic limitations. The theme of technological barriers refers to those that explicitly related to the technological problems such as technical robustness, specifications and functions. As society and technology are very much intertwined, a socio-technical theme was also identified. Barriers that fell into this category include definitions of technological appropriateness, local manufacturing, design of technologies and engineering methods, dissemination and adoption of technology, as well as marketing and advertising. Such a finding indicates once more that technology alone is not the sole component of development problems. Jeff Brown who works with Engineers without Borders USA agrees by saying: "The biggest challenges are cultural some things (technologies) get picked up and some don't. There is room for anthropologists and social scientists here to study."

In addition to the general category breakdown of key barrier themes listed in Figure 1, further analysis of the coded barrier categories provided a more in-depth analysis of key single barriers within those five categories. Figure 2 illustrates this qualitative breakdown of specific barriers and the number of times interviewees brought up a specific key barrier. As can be seen in Figure 2, the most single discussed barrier (twelve respondents) was the need for better collaboration with locals, NGOs and universities to share knowledge, data, and feedback so 
not to have to reinvent technologies and to re-learn from past mistakes. This barrier came mainly from category 1 from Figure 1. Similarly, better communication and access to knowledge was another top issue brought up by nine respondents and falling in the information category in Figure 1. Researchers spoke of the need to share details and design specs of successful projects, as well as problems and limitations encountered in the field. The collaboration barrier was mentioned by respondents from all fields interviewed and as such is a clear indicator of its severity. If agencies in the field do not have access to relevant knowledge, and if they do not share the tools and resources effectively, then their effectiveness and impact is significantly hampered. In addition, chances of passing that same knowledge and practices to communities for their own self-directed development is also likely to be poor. Given that all of the respondents were aware of the problem and want it resolved, it is clear that the intent to collaborate is present, but the right tools and platforms to facilitate the exchange of knowledge and collaboration appear to still be missing - or are at least are not widely known. Better linkages with other agencies in the field, knowing who has what technologies, skills and tools to offer, as well as having the ways to showcase one's technology or needs are sure to help minimize problems with technological dissemination and implementation. As Roger Salway and Bert Rivers from Compatible Technology International explain, it is not enough to just build the technology - one also has to advertise and find ways to showcase you have a better mousetrap.

The next biggest identified obstacle to AT development involved the actual process of technological dissemination and implementation (eight respondents) including the adoption issues. This barrier is from the combined social and technical category in Figure 1. Jason Morris, an industrial designer from Western Washington University who worked on a collaborative cargo bicycle design project in Uganda notes how "Implementation is a much harder problem than design, and includes barriers of manufacturing as well as acceptability and accessibility." Interviews also revealed that the dissemination barrier was linked to other social and cultural issues such as stable access to funding, time constraints, as well as linking those with technology to those who need the technology. Similarly, the transfer of technology and techniques used are just as important in dissemination as the technology itself, as mentioned by four interviewees. Furthermore, five respondents commented on the impeccable importance of preliminary research and surveys to determine the appropriateness of technologies and projects, while four interviewees emphasized the significance of project continuity and community feedback. Appropriate Technology Collaborative (ATC), Compatible Technology International (CTI), Appropriate Infrastructure Development Group (AIDG), Practical Action and Global Resolve all cite that background research and studies are crucial in learning the needs, purchasing power and composition of communities, and as such were key factors for the success of their projects.

The reality of socio-economic limitations facing rural and disadvantaged people was also brought up and coincides with previous studies. In short, the price of technology has to match the purchasing power of communities. Steve Crowe, from AIDG and Alterna, also commented that another key to a successful project implementation is in technological versatility. For example, the AIDG's bio-digesters were successful because 'They are good for people's health and environment, but also provide energy and can be a source of income.' As he says: 'When you're worried about when you get the food for the next day you're not going to think about environment, health and the long term future', and this is where versatility or multi-faceted components of a particular technology can have an even more of an impact and improve dissemination. The need for better linkage with other agencies and marketing coincides with five respondents bringing up the growing importance of business partnerships to move technologies and projects forward, as well as being more inclusive of the private sector to help facilitate dissemination and business opportunities. The reality of socio-economic limitations facing rural and disadvantaged people is also a major barrier because as John Barrie, Director of ATC explains: "Poor people are very cautious with spending the little money they have, so it takes time to develop trusting working relationships, and for people to commit to projects and systems they are unfamiliar with."

Within the economic barriers, both Moyo (2009) and Smillie (2000) as well as interviewees Vinay Gupta and John Barrie spoke of aid inefficiencies and problems of providing technology for free. Key drawbacks include lack of project continuity as well as market distortion because people may choose not to purchase a system in hope that a non-profit organization may come and bring one for free - which may or may not happen. This issue only strengthens the case to explore other creative financing options, such a micro-financing, in order to provide affordable life-saving solutions. Respondents such as Scott White (Kopernik), John Barrie (ATC) and Zubaida Bai (Ayzh) were particularly vocal about the potential of incorporating the private sector within development. Zubaida Bai explains 'Just because one thinks and works about social good doesn't mean one should live in poverty. One should be able to rise one's own livelihood and raise livelihood of others.' Scott White of Kopernik also notes that, 'This is an interesting time for social ventures, especially given the variety of business opportunities 
available through the World Wide Web'. Given the amount of respondents who commented on the problems of dissemination and uptake of technologies, problems of funding as well as aid, there is clearly room for social enterprises to enable healthy and creative marketplaces for the development of AT while working for and with communities that need them.

Another key barrier of AT uncovered in this study is that of the stigma associated with low-cost technologies. Seven respondents commented that AT is still considered low or second-rate technology. Zubaida Bai mentioned how 'some people do not even consider AT to be technology, or they do not see how even simple things can change someone's life'. Jason Morris agrees: 'There is a social stigma attached to bicycles and that is that they are poor people's technology. People ride cargo bikes only to be able to afford a motorcycle one day'. Activist Vinay Gupta comments how such mis-representation and low appeal of AT is one of the main culprits of poor public interest or funding by major agencies. Gupta is also quick to point out how structural competition between agencies for funding and projects also keeps AT out of the picture, which is an issue supported by the literature (Heyse, 2004; Moyo, 2009).

In terms of technology specific barriers, AT design, robustness, and the definition of AT were brought up as key components to a successful technological implementation. Bert Rivers from CTI emphasized the need to ensure technologies are robust and last, because once a technology become an integral part of a given community, as their food grinder did in Kenya, should something go wrong people's livelihoods are jeopardized once more. Within the same scope six respondents also commented on the importance of having a broad AT definition with an emphasis on culturally specific undertones which ensures that the design and reach of AT matches local conditions, needs and purchasing power. In conjunction with the dissemination barrier category, three interviewees spoke of high shipping costs as well as duty charged on imports as a challenge for the implementation of OSAT projects. Three interviewees (Toby Cumberbatch, Vinay Gupta, Steve Crowe) also commented that while there may not be such a thing as universal engineering that fits all conditions, there is something to be said about the universal appeal, functionality and robustness of technologies, such as cell-phones, which are being adopted rapidly throughout the world. There are general functions which can apply globally with locally specific undertones, for the need to design robust, efficient and relevant technologies with the focus on demand led innovation. As Nicolas Jequier notes the 'remarkable market receptivity to modern technology is not a coincidence: they are reliable, convenient, easy to use, relatively inexpensive and meet a need which traditional technology can either not meet or not as conveniently' (Jequier, 1976). Thus it can be inferred that OSAT needs to be held to the same technical standards in order to be met with the same success.

The feedback in the arena of intellectual property, open source and open access concepts; showed a lot of support on the ground level due to cutting costs and compatibility (eleven respondents). However, it was noted that there is still some convincing to be done of open source reliability and security compared to the traditional proprietary solutions. Open Data Movement activist David Eaves and a researcher from IDRC Canada agreed that a big component of this is in people intuition of open source product quality. David Eaves explains how 'free is not seen as trustworthy in terms of quality' given that 'people and governments are simply used to paying large amounts of money for products and services'. For Appropedia, ATC, Ayzh and Digital Green, open sourcing innovation and employing anti-proprietary solutions was a clear choice as these organizations were in part built on the concept. As Zubaida Bai points out, 'if the goal is high quality low cost solutions, IP would impede on that vision....the main thing is that technology reaches the intended people and if that happens with copying they as a business are ready for it.' Other respondents were open to OSAT principles, but felt there are still some issues to be worked out in regards to trust, privacy and security so one's invention or innovation is not exploited. The issue of trust was the main barrier to a greater open source engagement for three respondents, while simply having the time to participate was noted by two respondents. Given the novelty of open source and copy-left licenses, lack of trust and familiarity are significant barriers to overcome in order to inspire a much larger participation and engage critical mass building. Work done by Arduino processing, Open Source Ecology, RepRap 3-D printing, Appropriate Technology Collaborative and Appropedia are excellent examples of the working model, but more needs to be done to showcase the ease and effectiveness of open source enterprises for hardware designs.

Given the quantity of collaboration and communication barriers, it does not come as a surprise that a majority of interviewees were interested in the idea of an online database or a repository for knowledge with features to enable collaboration and exchange of data. For example, Dr. David Grimshaw of Practical Action, who has also worked with Science for Humanity and DFID, believes that in the future ideas will be developed very differently, much in the style of crowd-sourcing. As such, he explains "there has to be a way to pool resources, technologies and ideas together". Examples of this paradigm are already taking shape with AT online projects such as the (note 1) Appropedia Foundation, Catalytic Communities (CatComm) (note 2), and Engineering for Change (note 3), 
which could have a significant benefits for AT development (Pearce at al., 2011). However, there is also shortcoming of self-directed online learning, as Jeff Brown noted: 'The web is a great repository of knowledge, but it is not a substitute for actual work in the field' and 'there is a danger of convincing yourself you know all the answers'. This, as well as the problem of accountability for technical designs and knowledge can be an issue for the collaborative approach. However, precautions such as extensive peer-review, voting and rating systems can help validate and identify trusted content. Vinay Gupta of Hexayurt was also in support of open access and open source for better knowledge and technology exchange, but he emphasized the danger of competing databases resulting in too much scattered information, and the need to find ways to consolidate the knowledge and databases into one stream. Still, the power and the potential of Internet technologies for facilitation of development and knowledge are obvious. Using the example of William Kamkwamba (2009), a fourteen year old boy from Malawi who designed a windmill electricity system for his family home based on a photo he saw at a library, Gupta explains, "Ten years from now there will be 2 billion people with a broadband Internet access, but no toilet. It is likely to believe they will go online and find solutions and self-educate using the Internet."

The rise of "Do It Yourself" and "How-To websites", instructional videos and countless online databases and encyclopedias of knowledge is certainly an indicator of that trend. Building a network of AT designs and sustainable development methods, as well as facilitating participation in no small task. In addition, the theme of development is complex and includes a multitude of social, technical, political and economic variables however, a considerable progress can be made by more collaborative innovation in utilization of the Internet and communication technologies for a more open, effective and self-directed development.

\section{Limitations}

Although this study successfully confirmed literature identified barriers and expanded the research on OSAT, it did suffer from several limitations. While the organizations and individuals interviewed for this study are among the top in their field, they nonetheless represented only a portion of those working with ATs and therefore barriers presented here are not complete. The objective was to obtain an equal number of respondents from all sectors of OSAT involvement, but do to time and other limitations, the break-down is not equal in representation and this should be addressed in future studies. Future research should expand the list of interviewees as much as possible and include as many voices involved in the AT development. In addition, this research focused on the biggest barriers to AT and OSAT, and thus the list of barriers provided is not exclusive. Future work should also include a larger number of open sources and open access organizations and explore open source hardware barriers in relation to open source software. In addition, future work should also include viewpoints from the manufacturing AT industry, as well as of critics of appropriate technologies and those who see serious limitations to this kind of open collaborative development process. Finally, and most importantly, the future work should focus on obtaining feedback from communities employing the technologies to get further insight into their needs and viewpoints on barriers and development of AT.

\section{Conclusions}

The results of this study indicate that the primary barriers to the deployment of open source appropriate technology includes: 1) social barriers, 2) communication and information specific barriers, 3) barriers to open source technology, 4) barriers to technology (AT or in general), and 5) social and technical barriers connected.

The quantity and magnitude of social barriers was significant and often conjoined with technical and communication components. This indicates that technology alone cannot be expected to solve development problems as it is only one piece of the puzzle. The second most significant barrier identified by the interviewees was the need for better communication as well as access to information, signaling the need for more collaboration between agencies working in the field of sustainable development.

Further coding provided a more in-depth analysis of key single barriers. The greatest barrier identified was the need for more collaboration, better communication and exchange of knowledge, as well as concomitant problems of technological dissemination associated with appropriate technology. Additional barriers included the stigma of AT as inferior or "poor person's technology", barrier of cultural appropriateness, as well as problems of technological robustness, transferability and the fit within current industrial and economic systems. In addition, the need for better marketing, social venture opportunities and business partnerships were also viewed as increasingly important component for successful AT dissemination efforts. In general, interviewees were receptive to the core principles of knowledge commons, open source and innovation through collaboration and this may indicate a new positive trend in how knowledge is shared and built in future.

The results of this study demonstrate that the open source appropriate technology movement is incomplete and future work is needed to overcome the identified barriers. The interest and awareness of the benefits brought on 
by better collaborative methods is clearly established, and perhaps what is missing are the right tools and interfaces to allow for that collaboration to reach full capacity. This topic is worth pursuing in a much greater detail given the benefits of improved effectiveness and efficiency for researchers, organizations and communities working together to solve sustainable development challenges, and improve technological dissemination worldwide. More needs to be done to encourage, showcase and allow for open access / open source knowledge building to take place.

\section{Acknowledgments}

The authors would like to acknowledge helpful discussions with A. Goebel and would also like to thank all of the interviewees for their time and valuable insights.

\section{References}

Arunachalam, S. (2002). Reaching the unreached: how can we use information and communication technologies to empower the rural poor in the developing world through enhanced access to relevant information? Journal of Information Science. 28, 513-522. http://dx.doi.org/10.1177/016555150202800607

Ashraf, M. M., Swatman, P. \& Hanisch J. (2007). Some perspectives on understanding the adoption and implementation of ICT interventions in developing countries. The Journal of Community Informatics. 3 (4). [Online] Available: http://ci-journal.net/index.php/ciej/article/view/297/387

Benkler, Y. (2006). The Wealth of Networks: How Social Production Transforms Markets and Freedom. Yale University Press.

Black, M. (2007). The No-Nonsense Guide to International Development. New Internationalist.

Buitenhuis A., Zelenika, I. \& Pearce, J. M. (2010). Open Design-Based Strategies to Enhance Appropriate Technology Development. Proceedings of the $14^{\text {th }}$ Annual National Collegiate Inventors and Innovators Alliance Conference: NCIIA Open. 1-12. [Online] Available: http://nciia.org/sites/default/files/pearce.pdf

Carr, M. (ed). (1985). AT Reader: Theory and Practice in Appropriate Technology. Intermediate Technology Development Group.

Chambers, R. (1983). Rural Development - Putting The Last First. Longmans Scientific and Technical Publishers, New York: John Wiley.

Chesbrough, H. (2003). Open Innovation: The New Imperative for Creating and Profiting from Technology. Boston: Harvard Business School Press. http://dx.doi.org/10.1225/8377

Coomer, J. (ed). (1979). Quest for a Sustainable Society. Woodlands Conference on Growth Policy, Pergamon Press.

Deek F. \& McHugh, J. (eds). (2008). Open Source: Technology and Policy. Cambridge University Press.

Evans D. D. \& Adler, L. N. (ed). (1979). Appropriate Technology for Development: A Discussion and Case Histories. Westview Press, Boulder Colorado.

Felix R. \& Franklin, V. (1993). Finding New Routes in Old Paths: Linking Cultural Needs to Technical Knowledge - Appropriate Technology Inspires Developing Societies Concept, Controversy and Clarification. Bethany Books.

Hashmi, F. \& J. M. Pearce. (2011). Viability of Small-Scale Arsenic-Contaminated Water Purification Technologies for Sustainable Development in Pakistan, Sustainable Development. 19 (4), 223-234. http://dx.doi.org/10.1002/sd.414

Hazeltine B. \& Bull, C. (1999). Appropriate Technology: Tools, Choices and Implications, Academic Press.

Heyse, L. (2004). Beyond the Age of Humanitarianism: Past Trends and Future Challenges. Book Review Essay: Journal of Contingencies and Crisis Management. 11 (4), 178-183. http://dx.doi.org/10.1111/j.0966-0879.2003.01104004.x

Intergovernmental Panel on Climate Change (IPCC) (2007). Fourth Assessment Report: Climate Change. (eds) M.L. Parry, O.F. Canziani, J.P. Palutikof, P.J. van der Linden \& C.E. Hanson. Cambridge University Press, United Kingdom and New York, NY: USA.

Jequier, N. (ed). (1976). Appropriate Technologies: Problems and Promises. Development Centre of the Organization for Economic Co-Operation and Development. Paris.

Kamkwamba, W. (2009). The Boy Who Harnessed the Wind: Creating Currents of Electricity \& Hope. William 
Morrow.

Laumann, E. O. \& D. Knocke. (1987). The organizational state: Social choices in national policy domains. The University of Wisconsin Press, Madison, WI.

Mikkelsen, B. (1995). Methods of development work and research: A guide for practitioners. Sage Publications, New Delhi, India and London, UK.

Miles, M. \& M. Huberman. (1994). Qualitative Data Analysis: An expanded source book. Sage Publications, Thousand Oaks, CA and London UK.

Moyo, D. (2009). Dead Aid: Why Aid Is Not Working and How There is Another Way for Africa. New York: Farrar, Straus and Giroux.

NCAT News. (2011). National Center for Appropriate Technologies: Monitoring Federal Budget Talks. [Online] Available: http://www.ncat.org/news/index.php\#funding2011

Netcraft Web Survey, $2011 \quad$ [Online] Available: http://news.netcraft.com/archives/2011/01/12/january-2011-web-server-survey-4.html

Patton, M. (1990). Qualitative Evaluation Methods. Sage Publications, Newbury Park, CA and London, UK.

Pearce, J. M. (2007). Teaching Physics Using Appropriate Technology Projects. The Physics Teacher. 45, 164-7. http://dx.doi.org/10.1119/1.2709675

Pearce, J. M., Albritton, S., Grant, G., Steed, G., \& Zelenika, I. (2011). Enabling Innovation in Appropriate Technology for Sustainable Development, Sustainability: Science, Practice \& Policy (in press).

Pearce J. M., Blair, C. M., Laciak, K. J., Andrews, R., Nosrat, A. \& Zelenika Zovko, I. (2010). 3-D Printing of Open Source Appropriate Technologies for Self-Directed Sustainable Development, Journal of Sustainable Development. 3 (4), 17-29. [Online] Available: http://www.ccsenet.org/journal/index.php/jsd/article/view/6984

Pearce, J. M. \& Mushtaq, U. (2009). Overcoming Technical Constraints for Obtaining Sustainable Development with Open Source Appropriate Technology. Science and Technology for Humanity, IEEE Toronto International Conference, 814-820. http://dx.doi.org/10.1109/TIC-STH.2009.5444388

Pursell, C. 1993. The Rise and Fall of the Appropriate Technology Movement in the United States, 1965 - 1985. Technology and Culture. 34 (3), 629-37. http://dx.doi.org/10.2307/3106707

Rubin, A. \& Babbie. E. (2007). Essential Research Methods for Social Work. Brooks/Cole Belmont, CA.

Sawhney, N., Prestero, T., Griffith, S., \& Maguire, Y. (2002). ThinkCycle: Supporting Open Collaboration and Sustainable Engineering Design in Education. Development by Design, $2^{\text {nd }}$ International Conference on Open Collaborative Design for Sustainable Innovation, Bangalore, India, December 1-2

Schumacher, E. F. (1973). Small is beautiful: Economics as if people mattered. New York: Harper \& Row.

Smillie, I. (2000). Mastering the Machine: Poverty, Aid and Technology. ITDG Publishing.

Smith, J. (2009). Science and Technology for Development, Development Matters. Zed Books.

Tcheeko, L. \& M. N. Ntah. (2006). Information and Communication Technologies and Poverty Reduction in Developing Countries: the Case of Sub Saharan Africa countries. Systemics, Cybernetics and Informatics. 4 (6), 112-115. [Online] Available: http://www.iiisci.org/journal/sci/Contents.asp?var=\&previous=ISS7128

Tenner, E. (2007). Why Things Bite Back: Technology and the Revenge of Unintended Consequences. Vintage.

Tenner, E. (2009). Our Own Devices: How Technology Remakes Humanity. Vintage.

Thomas, J. R. (1994). What Machines Can't Do: Politics and Technology in the Industrial Enterprise. University of California Press.

UN report. (2010). Extra push needed on aid, trade and debt to meet global anti-poverty goals. International Development Co-Operation at a Crossroads in 2010. New York. [Online] Available: http://content.undp.org/go/newsroom/2010/september/un-reports-extra-push-needed-to-meet-global-anti-poverty -goals.en

Watson, T. (2009). Causewired: Plugging in Getting Involved, Changing the World. John Wiley \& Sons, Inc.

World Commission on Environment and Development (WCED). (1987). Our Common Future, Report of the World Commission on Environment and Development, Published as Annex to General Assembly document A/42/427, Development and International Co-operation: Environment August 2, 1987. 
http://dx.doi.org/10.2307/633499

World Health Organization (WHO). (2007). Facts and figures: Mortality report. [Online] Available: http://www.wpro.who.int/media_centre/fact_sheets/fs_20070801.htm

World Health Organization (WHO). (2010). Millennium Development Goals: progress towards the health-related Millennium Development Goals. World Health Organization, Geneva. [Online] Available: http://www.who.int/mediacentre/factsheets/fs290/en/

\section{Notes}

Note 1. http://www.appropedia.org/

Note 2. http://www.catcomm.org/en/

Note 3. https://www.engineeringforchange.org/home

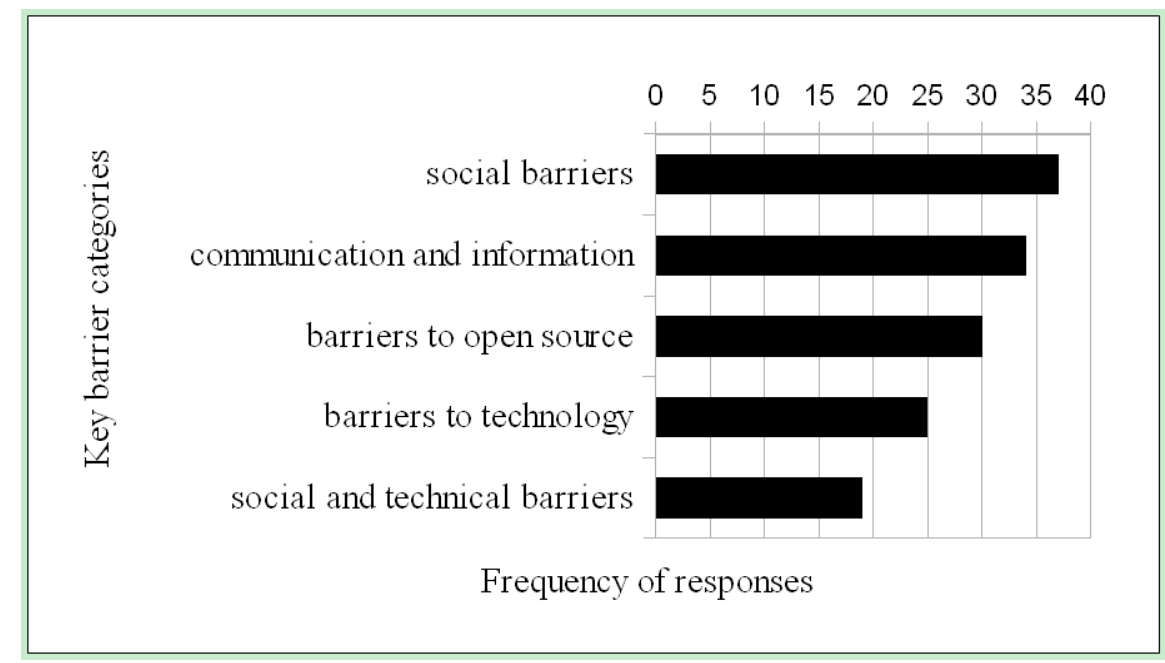

Figure 1. Frequency of response of key OSAT barrier categories

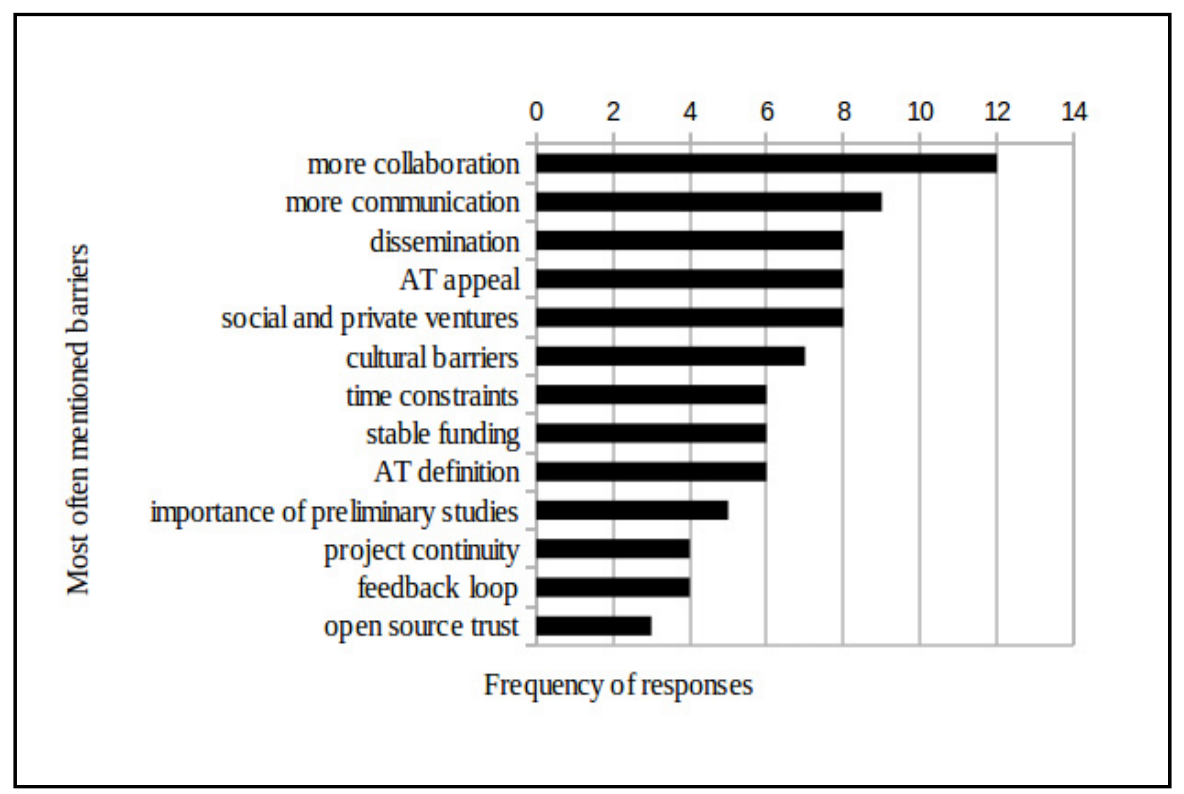

Figure 2. Frequency of responses of OSAT deployment barriers 